\title{
Results of the Transition Planning Inventory: Residential Independence for Individuals with Disabilities
}

\author{
Jane Finn ${ }^{1 *}$ and Alexandra Hutchinson ${ }^{2}$ \\ ${ }^{1}$ Division of Education and Special Education, Hope College, Holland, Michigan, United States \\ ${ }^{2}$ Division of Education, Hope College, Holland, Michigan, United States \\ Email: finn@hope.edu
}

\begin{abstract}
The Friendship House is an establishment where students without disabilities live with same aged individuals with intellectual disabilities. After years of this side-by-side living, a standardized assessment entitled the Transition Planning Inventory (TPI) was given to all stakeholders including roommates with and without disabilities and the parents of individuals with disabilities. Outcomes showed those adult living skills that were satisfactory as well as areas of needed improvement for those individuals with disabilities. Results gleaned from this research will help determine and identify critical transition planning areas for the individuals with intellectual disabilities whose goal is to live independently.
\end{abstract}

Keywords: Intellectual disabilities, independent living skills, post-school transition

\section{Introduction}

The Individuals with Disabilities Education Act (IDEA) guarantees access to education for students with disabilities while also addressing post-school outcomes (Office of Special Education Programs, 2000). Despite evidence that displays the positive impact that IDEA has had on people with disabilities, such as improvement in the numbers completing high school, using self help skills, and engaging in post secondary education (Wagner, Cameto, \& Newman, 2003) several studies have discovered that a great number of individuals with disabilities have not achieved post-school success as determined by residential independence (O'Hara, Cooper, Zovistoski, \& Buttrick, 2007; Woolf, Woolf, \& Oakland, 2010).

Living independently is shown to be an important goal shared by individuals with disabilities and their families (Ivey, 2007). Gaining living independence can be an obstacle for people with intellectual disabilities (Taylor, 2000; Wagner, Cameto, \& Newman, 2003). A low number of housing options that are available to these individuals are another roadblock to living independently (Karaim, 2012).

\section{Purpose}

With these housing problems in mind, a new residential initiative, named the Friendship House, was envisioned. The Friendship House was established as a small residence hall where individuals with intellectual disabilities could live side-by-side with similarly aged university students. The Friendship House is a unique residence hall that consists of four rooming suites or clusters, each containing three rooms for fully-abled university students and one room for an individual with an intellectual disability. Common areas such as the kitchen, laundry facilities, deck, and TV room are shared.

One of the original goals of the Friendship House was to promote independence in daily living of individuals with intellectual disabilities. The researchers asked the (1) roommates with disabilities, (2) roommates without disabilities, and (3) parents on how living at the Friendship House has impacted the individuals with disabilities' mastery of the transition skills necessary for independence as outlined by the IDEA as measured by a standardized instrument. 


\section{$3 \quad$ Method}

This study examined the independent living skills of individuals with moderate intellectual disabilities who lived semi-independently at the Friendship house. Human subjects approval was obtained prior to the research, and each participant gave consent to participate in the study.

\subsection{Participants and Setting}

For this research study, a purposeful sampling occurred. The study participants consisted of all the Friendship House residents (roommates who were disabled and non-disabled) and a parent or guardian of the individual with an intellectually disability (100\%). Each of the roommates with intellectual disabilities has resided at the Friendship House for more than three years. Table 1 shows the demographic breakdown for this study.

Table 1: Population, n, percentage participating, age range and gender of participants

\begin{tabular}{r|c|c|c|c}
\hline Population & $n$ & Percentage Participating & Age Range & Gender \\
\hline $\begin{array}{c}\text { Roommates } \\
\text { Nondisabled }\end{array}$ & 6 & $100 \%$ & $21-26$ & $\begin{array}{c}4 \text { males } \\
2 \text { females } \\
\text { Disabled }\end{array}$ \\
& 6 & $100 \%$ & $23-30$ & $\begin{array}{c}2 \text { females } \\
4 \text { males }\end{array}$ \\
\hline Parent/Guardian & 6 & $100 \%$ & & $\begin{array}{c}1 \text { male } \\
5 \text { females }\end{array}$ \\
\hline
\end{tabular}

\subsection{Instrument}

A standardized instrument entitled the Transition Planning Inventory (TPI) was used to evaluate and determine the strengths of the living skills of the individuals with disabilities. The TPI is a commonly used instrument in the special education and agency field to evaluate and determine the strengths of individuals in relation to post-secondary transitions in accordance to the federal IDEA regulations. The TPI focuses on nine general fields or subsections of adult living. The number of items on each transition construct is in parentheses: Employment (5 items), Further Education or Training (5 items), Daily Living (6 items), Leisure Activities (3 items), Community Participation (6 items), Health (6 items), Selfdetermination (5 items), Communication (4 items), and Interpersonal Relationships (6 items).

The TPI instrument contains three rater forms that are given to the individual with the disability, a parent or guardian, and one other observer (e.g. teacher, school personnel, roommate, etc.). Each rater grades the individual with a disability in respect to independent living abilities on a Likert scale of 0 to 5, 0 indicating "strongly disagree" and 5 indicating "strongly agree" that the individual with a disability has this trait. The participants also have the option to respond with DK ("don't know") or NA ("not applicable").

The raters' (roommates with and without disabilities and the parents/guardians of the individual with a disability) scores were averaged to determine the overall TPI scores. These individual scores are reported along with the total scores.

\section{Procedures and Data Analysis Methods}

A packet consisting of a formal invitation to participate, a consent form, and a self-addressed, stamped return envelope was mailed to the six roommates without disabilities, roommates with disabilities also known as "Friends" (please note that roommates with disabilities were own guardians - but in addition, the parents/guardians also gave this consent), and parents of the roommates with disabilities who were living in the Friendship House. Once the consent forms were received, another mailing occurred in which the participants were asked to complete the survey as thoroughly as possible and mail it back to the 
researchers in a self-addressed stamped envelope. All the individuals who signed the consent form participated $(n=12)$. The researchers orally gave the Transition Planning Inventory to the roommates with disabilities or Friends. $(n=6)$. To protect anonymity, participants were asked not to place their names on the survey. Instead, an identifying number was placed on the surveys, eliminating any potential risk or repercussions for the participants.

Because the TPI Likert scale ranged from 0-5, the data was coded from 0-5. Data was compiled on all areas of the TPI (Employment, Daily Living, Leisure Activities, Community Participation, Health, Selfdetermination, and Communication).

\section{$5 \quad$ Results}

The overall results show that no one group consistently reported high or low results in the subsections of the TPI. In fact, all roommates with disabilities (or Friends) scored a 2 or higher in all areas of the TPI. Figure 1 shows the TPI averages of all the Friends by self-report, parent and roommate without a disability. In addition, the results section will discuss what each Friend scored on the TPI.

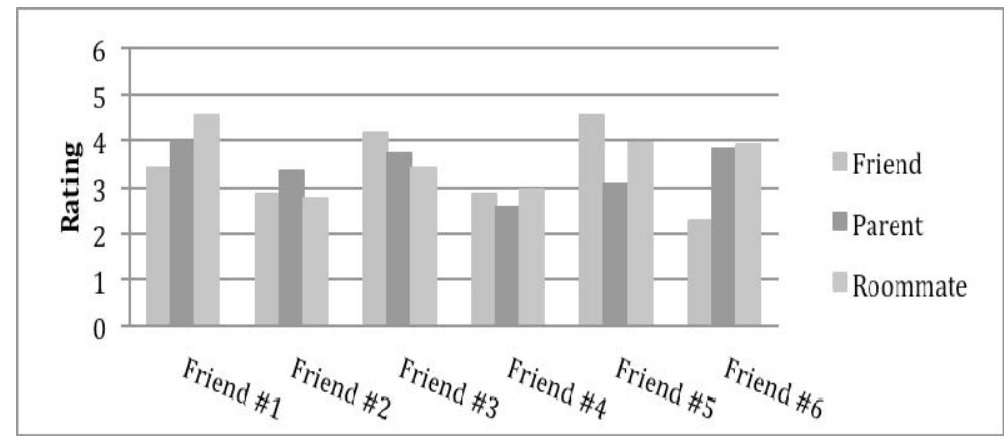

Figure 1: Individual friend's means for the TPI

Friend \#1. According to the TPI results, Friend \#1 scored highest in the subcategories of interpersonal relationships and self-determination. His or her average score for leisure activities was also higher than most others. The greatest area for growth with Friend \#1 is in the subsection of community participation. It is also intriguing to note that the friend, parent, and roommate scores for the further education category range vastly from 1.0 to 3.0 and even to 5.0 (see Table 2).

Table 2: Mean of the TPI for friend \#1 by friend, parent and roommate

\begin{tabular}{l|c|c|c}
\hline Subsection & & Rater & Roommate \\
\hline Employment & Friend & Parent & 4.2 \\
\hline Further Education & 2.8 & 3.4 & 5.0 \\
\hline Daily Living & 1.0 & 3.0 & 4.2 \\
\hline Leisure Activities & 3.8 & 3 & 5.0 \\
\hline Community Participation & 3.7 & 5.0 & 3.8 \\
\hline Health & 2.2 & 3.7 & 5.0 \\
\hline Self-Determination & 3.8 & 4.6 & 4.8 \\
\hline Communication & 4.0 & 4.6 & 5.0 \\
\hline Interpersonal Relationships & 3.8 & 4.5 & 5.0 \\
\hline
\end{tabular}

Friend \#2. When looking at the TPI results, it is recognizable that Friend \#2 scored highest in the subcategories of health and interpersonal communication. His or her average score for self-determination was also higher than most others. Friend \#2 scored substantially lower in the subsection of community participation than any other category. Another interesting comparison arises when viewing the scores 
from the three different raters for the category of further education. The friend and roommate both rated Friend \#2 with 1.8 and 1.0, respectively, while the parent gave Friend \#2 a score of 4.0. Refer to Table 3 for more data.

Table 3: Mean of the TPI for Friend \#2 by friend, parent and roommate

\begin{tabular}{l|c|c|c}
\hline Subsection & Friend & $\frac{\text { Rater }}{\text { Parent }}$ & Roommate \\
\hline Employment & 3.8 & 3.2 & 3.2 \\
\hline Further Education & 1.8 & 4.0 & 1.0 \\
\hline Daily Living & 3.0 & 4.0 & 3.0 \\
\hline Leisure Activities & 2.0 & 3.7 & 2.0 \\
\hline Community Participation & 1.5 & 0.4 & 0.0 \\
\hline Health & 3.8 & 4.2 & 4.0 \\
\hline Self-Determination & 3.0 & 3.6 & 4.2 \\
\hline Communication & 2.0 & 2.3 & 2.0 \\
\hline Interpersonal Relationships & 3.7 & 4.0 & 3.8 \\
\hline
\end{tabular}

Friend \#3. According to the TPI results, Friend \#1 scored highest in the subcategories of interpersonal relationships and leisure activities (see Table 4). His or her average score for selfdetermination was also higher than most others. The greatest area for growth with Friend \#3 is in the subsections of health and daily living.

Table 4: Mean of the TPI for Friend \#3 by friend, parent and roommate

\begin{tabular}{l|c|c|c}
\hline$\underline{\text { Subsection }}$ & & \multicolumn{1}{|l|}{ Rater } & Roommate \\
\hline Employment & Friend & Parent & 3.0 \\
\hline Further Education & 4.4 & 5.0 & 3.3 \\
\hline Daily Living & 5.0 & - & 2.8 \\
\hline Leisure Activities & 2.7 & 3.8 & 3.0 \\
\hline Community Participation & 5.0 & 4.7 & 2.2 \\
\hline Health & 4.7 & 4.0 & 3.2 \\
\hline Self-Determination & 3.3 & 1.8 & 4.2 \\
\hline Communication & 4.5 & 3.6 & 5.0 \\
\hline Interpersonal Relationships & 3.8 & 4.0 & 4.2 \\
\hline
\end{tabular}

Friend \#4. Friend \#4 scored highest in the TPI subcategory of leisure activities. His or her average score for employment was also higher than most others. Friend \#4 scored substantially lower in the subsections of community participation and further education than any other category. Another interesting comparison arises when viewing the scores from the three different raters for the category of further education (see Table 5). The friend and roommate both rated Friend \#4 with 2.5 and 3.5, respectively, while the parent gave Friend \#4 a score of only 0.7.

Friend \#5. According to the TPI results, Friend \#5 scored highest in the subcategories of interpersonal relationships and self-determination. His or her average score for leisure activities was also higher than most others. The greatest area for growth with Friend \#5 is in the subsection of further education. It is also intriguing to note that the friend, parent, and roommate scores for the communication category range vastly from 4.5 and 5.0 and even down to 0.0 (see Table 6). 
Table 5: Mean of the TPI for Friend \#4 by friend, parent and roommate

\begin{tabular}{l|c|c|c}
\hline Subsection & Friend & $\frac{\text { Rater }}{\text { Parent }}$ & Roommate \\
\hline Employment & 2.2 & 3.0 & 4.7 \\
\hline Further Education & 2.5 & 0.7 & 3.5 \\
\hline Daily Living & 2.8 & 2.3 & 4.0 \\
\hline Leisure Activities & 3.7 & 3.3 & 3.7 \\
\hline Community Participation & 2.2 & 1.2 & 1.8 \\
\hline Health & 2.8 & 2.8 & 3.5 \\
\hline Self-Determination & 2.6 & 3.4 & 2.4 \\
\hline Communication & 3.0 & 2.3 & 1.0 \\
\hline Interpersonal Relationships & 3.8 & - & 3.5 \\
\hline
\end{tabular}

Table 6: Mean of the TPI for Friend \#5 by friend, parent and roommate

\begin{tabular}{l|c|c|c}
\hline Subsection & Friend & $\frac{\text { Rater }}{\text { Parent }}$ & Roommate \\
\hline Employment & 4.8 & 2.6 & 4.2 \\
\hline Further Education & - & 1.4 & 4.0 \\
\hline Daily Living & 4.8 & 3.2 & 4.8 \\
\hline Leisure Activities & 5.0 & 3.3 & 4.0 \\
\hline Community Participation & 4.6 & 2.0 & 3.7 \\
\hline Health & 4.2 & 3.2 & 4.5 \\
\hline Self-Determination & 3.4 & 3.4 & 5.0 \\
\hline Communication & 5.0 & 4.5 & 0.0 \\
\hline Interpersonal Relationships & 5.0 & 4.3 & 4.7 \\
\hline
\end{tabular}

Friend \#6. When looking at the TPI results, it is recognizable that Friend \#4 scored highest in the subcategories of self-determination and leisure activities. His or her average score for interpersonal relationships was also higher than most others. Friend \#4 scored substantially lower in the subsections of community participation and further education than any other category. Another interesting comparison arises when viewing the scores from the three different raters for the category of employment (see Table 7). The parent and roommate both rated Friend \#6 with 4.2 and 3.8, respectively, while the Friend gave Friend \#6 a score of only 1.6.

Table 7: Mean of the TPI for Friend \#6 by friend, parent and roommate

\begin{tabular}{l|c|c|c}
\hline Subsection & Friend & $\begin{array}{c}\text { Rater } \\
\text { Parent }\end{array}$ & Roommate \\
\hline Employment & 1.6 & 4.2 & 3.8 \\
\hline Further Education & 1.6 & 3.0 & 1.0 \\
\hline Daily Living & 2.3 & 4.2 & 4.3 \\
\hline Leisure Activities & 3.0 & 3.7 & 4.0 \\
\hline Community Participation & 1.2 & 2.7 & 3.3 \\
\hline Health & 2.2 & 4.0 & 4.8 \\
\hline Self-Determination & 3.0 & 4.1 & 4.0 \\
\hline Communication & 2.5 & 4.0 & 4.0 \\
\hline Interpersonal Relationships & 3.3 & 4.2 & 3.4 \\
\hline
\end{tabular}




\section{Discussion and Conclusion}

Living independently is one of the hallmarks of being an adult and transitioning successfully from school to post secondary life. Through this study, we sought to understand the which IDEA transition components according to the TPI were the highest and one which were the areas that needed improvement for the individuals with disabilities living at the Friendship House.

According to our study, the highest transition areas of communication and leisure activities were also supported by research data as being necessary and prominent skills for individuals with disabilities to work toward (Eratay, 2013; Lord, 1997). Research also has been done to validate the data from this study claiming that community participation and further education are areas of growth for individuals with disabilities (Westling, Kelley, Cain \& Prohn, 2013; Amado, Stancliffe, McCarron \& McCallion, 2013).

The Friendship House is a good model for developing the appropriate skills for independent living for those individuals with intellectual disabilities. These residents scored average to above on these transition areas: communication, interpersonal relationships, leisure activities, and health. The highest transition areas were the subsections of communication and leisure activities.

As a result of this research, the Friendship House personnel, roommates without disabilities, and families have the opportunity to recognize and praise their friends for the transition areas in which they are being successful. These results also give these personnel and families the information necessary in order to focus their attention on their friends' specific transition skills that need improvement. Considering a larger view, this house could be a model for other residential halls at other university campuses around the country. In conclusion, by taking an all-around look at the goals of this research and the outcomes that it has provided, one has the tools necessary to help individuals with disabilities to each have a better quality of life.

\section{References}

1. Amado, A. N., Stancliffe, R. J., McCarron, M., \& McCallion, P. (2013). Social inclusion and community participation of individuals with Intellectual/Developmental disabilities. Intellectual and Developmental Disabilities, 51(5), 360-375.

2. Eratay, E. (2013). Effectiveness of leisure time activities program on social skills and behavioral problems in individuals with intellectual disabilities. Educational Research and Reviews, 8(16),1437-1448.

3. Ivey, J. (2007). Outcomes for students with autism spectrum disorders: What is important and likely according to teachers. Education and Training in Developmental disabilities, 42(1), 3-13.

4. Lord, M. A. (1997). Leisure's role in enhancing social competencies for individuals with Developmental Disabilities.Research Update. Retrieved from http://0-search.proquest.com.lib.hope.edu/dosview/62626013

5. Karaim, R. (2012). People with Mental Retardation. Housing First. A Special Report from National Public Radio. Retrieved from: http://www.npr.org/news/specials/housingfirst/whoneeds/mentalretardation.html

6. O'Hara, A., Cooper, E., Zovistoski, A., \& Buttrick, J. (2007). Priced out in 2006: The housing crisis for people with disabilities. Consortium for Citizens with Disabilities Housing Task Force.

7. Office of Special Education Programs. (2000). Students with disabilities exiting special education (Publication No ED 400573). Retrieved from http://edgov./pubs/OSEP9AnlRpt/chap2c.html

8. Taylor, H. (2000). Conflicting trends in employment of people with disabilities 1986-2000. Harris Poll \#59. Retrieved from http://www. harrisinteractive.com/harris_poll/index.asp?PID=121

9. Wagner, M., Cameto, R., \& Newman, L. (2003). Youth with disabilities: A changing population. A special topic report of findings from the National Longitudinal Transition Study-2 (NLTS2). Menlo Park, CA: SRI International. Retrieved from www.nlts2.org/pdfs/execsum_changepop.pdf

10.Westling, D. L., Kelley, K. R., Cain, B., \& Prohn, S. (2013). College students' attitudes about an inclusive postsecondary education program for individuals with intellectual disability. Education and Training in Autism and Developmental Disabilities, 48(3), 306-319.

11.Woolf, S., Woolf, C., \& Oakland. T. (2010). Adaptive behavior among adults with intellectual disabilities and its relationship to community independence. Intellectual and Developmental Disabilities, 48(3), 209-215. 